\title{
Immigration and the UK: Reflections After Brexit
}

\author{
Marco Alfano, University of Strathclyde and CReAM \\ Christian Dustmann, UCL and CReAM \\ Tommaso Frattini, University of Milan, LdA and CReAM
}

$\underline{\text { September } 2016}$

\section{Introduction}

The recent referendum in the UK on membership of the EU has sent shockwaves across the political establishment not just in the UK itself and throughout Europe, but also around the world. In the runup to the referendum, economists were (perhaps for the first time) united in pointing out that the economic case for Brexit is rather slim, that hardly any well-argued reason could be given by the Brexit camp as to why it may be a good idea to leave the EU, and that the economic consequences could be severe.

That lack of economic argument in favour of Brexit, which should have been the key battleground in the run up to the referendum, led the debate to focus on one particular issue-immigration. Like the free movement of goods, capital, and services, a fundamental pillar of the EU, and a nonnegotiable requirement for any new member state, is the free movement of people. It was this particular aspect of EU membership that became the strongest single assertion of the Brexit camp. The inability to control immigration from within the EU was made a symbol for everything else Brexit stood for (such as the idea of 'sovereignty' or the pain of being subjugated to 'rules made in Brussels and not the UK'), but - again - fact-based arguments against free mobility on economic or welfare grounds were hard to find. Nevertheless, free mobility within the EU quickly became the scapegoat for the economic and social woes that had distressed the country since the Great Recession, and perhaps even earlier, such as crime, real wage decline, inequality, unemployment, access to social services, health provision, and benefits and transfers. 'Immigration' and everything people associated with it and were encouraged to believe by a relentless campaign of the majority of the tabloid press contributed decisively to the decision that the UK took on 23 June 2016. Immigration and free mobility will likely again be central in the negotiations between the UK and its European partners in developing a model for Brexit that minimises the economic costs for both the UK and the EU. 
In this chapter, we reassess the case of migration as a reason for the UK to leave the EU. We provide evidence that relates to some of the claims made in the run up to the referendum, and that will certainly matter again in Brexit negotiations. Much of the material we provide in this chapter draws on previous research by us and others.

The structure of the chapter is as follows. In the next section, we describe some key features of immigration in the UK, and put it into perspective with the experience of other advanced economies. In the third section, we review the existing evidence of the effects of immigration on the UK labour market and public finances, and the fourth section concludes.

\section{Immigration to the UK}

\section{Overall trends}

The movement of people across national borders has increased rapidly over the past two decades. According to United Nations estimates, while in 1995 the world stock of international migrants amounted to about 161 million people ( $2.8 \%$ of the world population), by 2015 the global migrant stock reached almost 244 million (3.3\% of the world population) (United Nations 2015). These figures exclude migration within countries, which for China alone amounts to 120 million rural immigrants in cities population (United Nations 2011), and the figures also certainly undercount illegal immigrants. The increase has been substantial, especially in the more developed countries. The 1995 stock of immigrants in Europe, Northern America, Australia/New Zealand and Japan was 92 million ( $7.9 \%$ of the population), but increased to more than 140 million (11.2\% of the population) by 2015 (United Nations 2015).

\section{[Figure 1 here]}

Figure 1 displays the share of foreign born in the population for a selected number of countries and for the years 2000 and 2015. Two things stand out from this figure. First, the percentage of foreign born in the populations of many European countries - including Germany, Austria and Switzerland - is by now higher than that in the US. Second, the percentage of foreign born in the population has been increasing in every country, and in some by a large margin. The UK is neither among the displayed countries with the highest share of foreign born in 2015 (in fact, it is in the low-tomedium range), nor is it among the countries with the highest increase in its foreign born population, although the importance that has been attached to immigration in the UK debate would seem to suggest just that, as we will show next.

[Figure 2 here] 
In Figure 2, we display - from the European Barometer - the importance individuals attach to immigration and to three other issues: crime, unemployment, and the economy. The top panel displays this for the UK for 2015, and contrasts it with the EU average. While $35 \%$ of UK citizens believe that immigration is one of the two most important issues facing their country, this is the case for only $23 \%$ on average across the EU. While at the EU level unemployment is the primary source of concern, with more than $40 \%$ of EU citizens indicating it as one of the two most important issues facing their country, in the UK this share is just above $20 \%$. Immigration ranks first among the concerns of British citizens.

The bottom panel displays how concerns over immigration have evolved over time in the UK and in other EU countries. The vertical axis carries the percentage of individuals who considered immigration to be one of the two most important issues facing their country, whereas on the horizontal axis we display the year in which the respective question was asked. The UK is the country where, compared to other concerns, concern about immigration is consistently highest. The only exceptions are in 2007, when relative concerns over immigration are higher in Spain (a country that was experiencing an extraordinarily rapid growth of its immigrant population), and in 2015, when, compared to other concerns, immigration is a stronger concern in Germany (which followed around 1 million refugees being accommodated by the country in that year alone). In 2015 concerns about immigration also became stronger, relative to other concerns, in Italy and in the EU as a whole, as a consequence of the refugee crisis (which did not affect the UK).

[Figure 3 here]

How do the immigrants who arrive in the UK compare to immigrant populations in other countries? Figure 3 shows that the share of highly educated among immigrants in the UK is substantially higher than in any other EU country. According to Eurostat data, in 2015, 47\% of immigrants in the UK in the 15-64 age range had achieved a tertiary education, which contrasts starkly not only with Italy $(12 \%)$ and Greece (15\%), but also with countries such as Germany (19\%), France (29\%) and even Sweden (36\%) and Switzerland (38\%). Across the EU27, the average share of immigrants with a tertiary education is 30\%. Only Poland (50\%) and Ireland (48\%) (not reported in Figure 3) have a higher share of tertiary-educated immigrants than the UK, but in the case of Poland, the foreign born population constitutes only $1.7 \%$ of the total population in $2013 .^{1}$

To summarise, the share of foreign born among the overall population is smaller in the UK than in many other European countries, and the inflow of immigrants into the UK over the past one and a

${ }^{1}$ Source: OECD International Migration Database 2015. 
half decades has been more modest than that experienced by some other European countries. On the other hand, migration has consistently been a larger concern for UK citizens than for citizens of the $\mathrm{EU}$, and topped the issues of concern in the year before the referendum. This is surprising as immigrants to the UK are highly skilled and have high employment rates compared to immigrants in other European countries. ${ }^{2}$ We now turn in more detail to the different aspects of immigration to the UK.

\section{Recent immigration to the UK: Key facts}

Over the past 15 years, the UK has experienced a sizable growth in its foreign-born population although, as illustrated above, not out of line compared to other countries. According to the UK Labour Force Survey (LFS), between 2002 and 2015, the immigrant population in the UK increased by 3.7 million individuals, from 4.9 million to 8.6 million (a $76 \%$ increase). ${ }^{3}$ As a result of this growth, immigrants accounted for $13.3 \%$ of the total UK population in 2015.

In the public perception, this rapid growth has been typically associated with the two rounds of EU eastern enlargement that took place in 2004 and 2007. However, according to the LFS, nonEuropean immigrants still form the majority of the UK immigrant population, with 5.4 million individuals living in the UK who were born in a country outside of the European Economic Area (EEA) in 2015, compared with 3.1 million immigrants from EEA countries. Furthermore, nonEuropean immigrants accounted for most of the inflow over the period: according to the LFS, between 2002 and 2015 the net immigration from non-EEA countries stood at just over 2 million, whereas net immigration from EEA countries was only 1.6 million.

[Figure 4 here]

In Figure 4, we provide estimates of the net inflow of EEA and non-EEA immigrants to the UK in each year between 2004 and 2015, based on the Long-Term International Migration Estimates (LTIM) of the Office of National Statistics (ONS). ${ }^{4}$ According to these figures, net EEA inflows

\footnotetext{
${ }^{2}$ In 2015, the employment rate of foreign citizens in the UK was $74 \%$ compared to an EU average of $64 \%$ (http://ec.europa.eu/eurostat/statistics-explained/index.php/Migrant_integration_statistics_-_employment\#Employment, accessed on 26/9/2016).

${ }^{3}$ Our main data source for statistics on migrants is the UK Labour Force Survey (LFS). The LFS is the largest household survey in the UK, consisting of interviews with around 40,000 households and 100,000 individuals. The survey is intended to be representative of the UK population and provides the official measures for employment and unemployment.

${ }^{4}$ These estimates are drawn from a number of sources, but they are based mainly on the International Passenger Survey (IPS). The IPS is a voluntary sample based survey collecting information about passengers entering and leaving the UK, and thus provides information on both migrant inflows and outflows. The ONS complements the IPS data with information drawn from the LFS, Home Office immigration administrative systems, and data from the Northern Ireland Statistics and Research Agency. Estimates of net flows based on the LFS show a similar trend, but differ somewhat in magnitude. This illustrates that the measurement of net migration inflows is challenging, and subject to considerable measurement problems.
} 
were substantially smaller than non-EEA inflows in all years. ${ }^{5}$ Additionally, over this period, nonEEA net immigration has always been above 100,000 thousand net entries per year. Therefore, the promise of the last government in April 2011 to bring net migration down below 100,000 has not even been fulfilled for non-EEA immigration, which in principle can be controlled. ${ }^{6}$ According to ONS figures, the 100,000 limit has been consistently breached with non-EEA inflows alone. Thus, the perception that was created during the Brexit campaign that EEA migration is responsible for not achieving the government's target of 100,000 is certainly incorrect. The fact that, despite the political pressure on the government to bring down migration over the past few years, the target has not even been reached for non-EEA immigrants suggests very strong economic reasons for immigration - something that we will take up below.

[Table 1 here]

Table 1 describes in more detail the UK's immigrants - their age and education structure, their wages and employment rates, and how they compare to natives, based on the LFS for the year 2015. Whilst the average age of immigrants and natives is similar, at around 40 years, immigrants from the EEA tend to be slightly younger (around 37 years) and immigrants from outside the EEA slightly older (around 41 years). The proportion of individuals of working age is considerably higher among immigrants - around $53 \%$ of the native population is aged 23 to 65 , whereas $72 \%$ of migrants fall within this age range. By contrast, $19 \%$ of natives are aged 65 or above, compared to only $12 \%$ of migrants.

In Figure 3 we have already illustrated that migrants to the UK are better educated than those to other European countries. Table 1 shows that this is also the case when we compare the UK's immigrant populations with the native born population. On average, migrants report higher educational attainments compared to natives. We measure educational attainment by the age at which individuals left full-time education, and define individuals who ended full-time education aged 16 or younger as 'low education' individuals. While $45 \%$ of UK-born individuals fall into this category, the figure for immigrants is only $18 \%$. The corresponding percentage is lower for immigrants from the EEA (13\%) than for immigrants from outside the EEA (20\%). The percentage of individuals classified as 'medium education' - i.e. individuals who left-full time education between the ages of 17 and 20 - is 30\% for natives and 33\% for migrants. Finally, we classify individuals who left full time education aged 21 or older as 'high education' individuals. This figure is considerably higher for immigrants than for natives $-42 \%$ for the former compared with $24 \%$ for

\footnotetext{
${ }^{5}$ According to the LFS, net EEA inflows were substantially smaller than non-EEA inflows until 2009, while there is some variability in subsequent years.

${ }^{6}$ See http://www.bbc.co.uk/news/uk-politics-13083781 for a summary of David Cameron's speech.
} 
the latter. The corresponding percentage is similar for migrants from the EEA (43\%) and from outside the EEA (41\%).

The labour market outcomes of natives and immigrants differ considerably. Table 1 shows that the employment rate (defined as the ratio of employed individuals aged 23-65 to total population in the same age range) is around $78 \%$ for UK-born individuals, compared with $74 \%$ for immigrants. However, this average masks considerable differences. Immigrants from the EEA have considerably higher employment rates (around 83\%) compared with immigrants from outside the EEA (70\%). The average weekly earnings of immigrants (£490) exceeds that of natives (£478). The weekly earnings for immigrants from outside the EEA are particularly high at around $£ 514$, whereas earnings of immigrants from inside the EEA are slightly lower than natives at around $£ 452$.

Overall, these figures suggest that immigrants from the EEA are better educated than natives and have higher employment rates, both in comparison to natives and non-EEA immigrants. Despite their higher education, the wages of EEA immigrants are below those of the other groups something we take up below.

\section{The economic impact of immigration to the UK}

\section{Jobs and immigrant employment}

Does immigration affect native employment? The issue is controversial and has been the subject of several empirical studies. Early work by Dustmann et al. (2005) did not detect any statistically significant employment effects of immigration to the UK over the period 1983 to 2000. Likewise, Lemos and Portes (2008) do not find any effect of A8 immigration (i.e. immigration from Czech Republic, Estonia, Hungary, Latvia, Lithuania, Poland, Slovakia and Slovenia) on the number of unemployment claimants in 2004-2005. More recent work on the employment effects of immigration to the UK confirms these findings for later years. Lucchino et al. Portes (2012) find no association between migrant inflows and unemployment claimants over the years 2002 to 2011, and no evidence of a more adverse impact of immigration during the recent recession. The Migration Advisory Committee conducted an extensive analysis of the association between immigration and native employment in the UK between 1975 and 2010 (Migration Advisory Committee 2012), which does not provide causal estimates, however, but simple correlations. Their analysis shows that, over the whole period, there is no systematic association between overall immigration and native employment. However, they do detect a negative correlation between non-European migration and native employment in more recent years (1995-2010) and during economic 
downturns. Importantly, the study does not find any correlation between EU immigration and native employment in any period.

[Figure 5 here]

There is therefore a consensus among most of the literature that immigration did not affect the employment prospects of the UK-born population. Here, we will inspect the recent trends in the UK (see Wadsworth et al. 2016 for a similar analysis). In Figure 5, based on the LFS, we plot the evolution of the share of immigrants in the population aged 16-65 (i.e. the potential labour force) on the right-hand axis, and the evolution of the unemployment rate of UK natives (defined as the ratio of unemployed to the labour force) between 2002 and 2015 on the left-hand axis. The figure illustrates that there is no systematic correlation between immigration and native unemployment. While the stock of immigrants in the UK increases at a steady pace over the entire observation window, unemployment also increases between 2002 and 2008, jumps up in 2009 and 2010 by more than two percentage points as a result of the Great Recession, and then declines from 2011 onwards. The increases in both immigration and unemployment between 2002 and 2008 in no way suggest that immigration causes unemployment, only that the two series are correlated over that period. Neither do the contrasting trends for both after 2011 suggest that immigration was the cause for the drop in unemployment. However, the two series clearly show that unemployment has dropped quite dramatically over the past years, despite an increase in immigration. That must mean that more jobs have been created than those that went to new arrivals. Two observations are remarkable in that series. The first is the fact that the stock of immigrants continued to grow throughout the Great Recession at basically the same pace as before and afterwards. The second is the extraordinary ability of the British economy to create jobs after the Great Recession.

\section{Wages}

Another common, labour market-related fear regarding immigration is that it may depress the wages of native workers. Economic reasoning suggests that immigration may hold back wage growth of natives who compete with immigrants, while at the same time increasing wage growth for native workers whose skills are complementary to those of natives (see Dustmann et al. 2008 for the simplest possible model). In order to assess the wage effects of immigration, it is therefore important to understand the types of natives that immigrants compete with. This is not always an easy task, since immigrants downgrade upon arrival, thus making it difficult to predict who they will compete with. Dustmann et al. (2013) circumvent this problem by defining immigrants' skill 
group in terms of their position in the native wage distribution. ${ }^{7}$ They first demonstrate that immigrants to the UK between 1997 and 2005 are, on average, much better educated than natives. However, due to occupational downgrading, recent immigrants are located at the lower end of the native wage distribution, and it is here that they put competitive pressure - if they do so at all - on native wages. Dustmann et al. (2013) find that immigration over the period from 1997 to 2005 has held back wage growth below the $20^{\text {th }}$ percentile, but only by a very small amount. Over that period, the real hourly wage increased by $4.28 \%$ per year in the 1 st decile, and immigration held wage growth back by only $0.21 \%$. On the other hand, immigration has increased wages above the $20^{\text {th }}$ percentile quite substantially so that overall, immigration to the UK over the period considered has had a positive impact on average native wages. In a related paper based on data for the years 1975- 2005, Manacorda et al. (2012) argue that the group whose wages has been slightly depressed by immigration is previous immigrants now living in the UK.

\section{[Figure 6 here]}

The overall pattern of where more recent immigrants are likely to be found in the native wage distribution is similar to that for the period considered in the study by Dustmann et al. (2013). In Figure 6, we display the actual and predicted distribution of immigrants along the wage distribution of native workers over the period 2002-2015, distinguishing between EEA and nonEEA immigrants (in the top and the bottom panels) and between immigrants who have been in the country for less than 2 years, for 2 to 4 years, for 5 to 10 years, and for more than 10 years. The horizontal line shows as a reference the native wage distribution. The estimate of immigrant densities are above the horizontal line in those parts of the native wage distribution where immigrants are more concentrated than natives, and below the horizontal line in the parts of the distribution where immigrants are less concentrated than natives. ${ }^{8}$

The density of immigrants that arrived within the previous two years is given by the dashed red lines in the figure. It is higher than that of natives everywhere below the $25^{\text {th }}$ percentile of the wage distribution, regardless of their origin. On the other hand, it is lower between the $25^{\text {th }}$ and the $90^{\text {th }}$ percentiles, and - for non-EEA immigrants only - higher again beyond the $90^{\text {th }}$ percentile. This seems surprising, given the higher educational attainment of immigrants, as we have illustrated in Table 1. Indeed, if we were to predict the position of recent immigrants in the native wage distribution based on their observed characteristics (age, gender and education), their density would

\footnotetext{
${ }^{7}$ See also Dustmann, Schoenberg and Stuhler (2016) for a refined methodology.

${ }^{8}$ The figures are not corrected for return migration. However, what matters for the wage impact of immigration is where immigrants who are in the UK are located along the wage distribution, not where they would have been located had they not left the country.
} 
be illustrated by the black solid line - EEA immigrants' distribution would closely resemble that of natives, whereas non-EEA immigrants would more concentrated in the upper part and less concentrated in the bottom part of the distribution. The reason is that immigrants downgrade upon arrival, i.e. they initially work in jobs that are below their educational level, due to a lack of skills such as language that make them equally productive to natives with the same level of education. Over time, however, immigrants acquire these skills and climb up the job ladder, so can found in areas of the wage distribution that are more in line with their skills. This can be seen in the other lines in the two figures, which refer to immigrant populations with longer durations in the UK. The immigrant densities become increasingly similar to those predicted based on their age-education profiles - for both EEA and non-EEA immigrants - the longer they spend in the UK.

This indicates that, as time spent in the UK increases, immigrants affect the relative supply of different types of labour less and less, thus easing the pressure exercised on the wages of natives at the bottom of the distribution, but also the positive effect on wages higher up.

\section{Public resources}

Another frequently held concern about immigration is that it puts excessive demand on public services, which are unable to cope with the increased population. This view is often expressed by pundits and politicians, including members of the current and former government. For instance, Prime Minister Theresa May said in her speech at the Conservative Party conference in May 2015 that "when immigration is too high, when the pace of change is too fast, it's impossible to build a cohesive society. It's difficult for schools and hospitals and core infrastructure like housing and transport to cope ${ }^{, 9}$ and former prime minister David Cameron, in his speech on immigration on 21 May 2015 said "if you have uncontrolled immigration, you have uncontrolled pressure on public services". 10

It is certainly true that population changes - whether declines or increases - change the demand for public services. However, the key questions when it comes to immigration are whether those who arrive and demand services pay for them in terms of taxes, and whether the tax payments actually result in the redirection of resources towards the areas where the services are demanded. In recent work (Dustmann, et al. 2010 and Dustmann and Frattini 2014; see also Preston 2014 for a general discussion), we address the first question, showing that in particular immigrants from the EEA have

\footnotetext{
${ }^{9}$ http://www.bbc.com/news/uk-politics-34450887

${ }^{10}$ https://www.gov.uk/government/speeches/pm-speech-on-immigration
} 
paid far more in taxes than they received in the form of transfers and benefits. Our results show that over the period 2001-2011, immigrants who came to the UK since 2000 were $43 \%$ (17 percentage points) less likely to receive state benefits or tax credits. These differences are partly attributable to the more favourable age-gender composition of immigrants. However, even when compared with natives of the same age, gender composition and education, recent immigrants are still 39\% less likely than natives to receive benefits. Distinguishing between the different immigrant groups, immigrants from the ten Central and Eastern European countries that joined the EU since 2004 (A10) and non-EEA immigrants have about a 16 percentage point lower probability of receiving transfers and tax credits than natives, and the probabilities are even smaller (by about 23 percentage points) for immigrants from the other EEA countries. Recent immigrants overall are also 1.2 percentage points less likely than natives to live in social housing, a probability gap that increases to 6 percentage points for recent A10 immigrants and to more than 9 percentage points for recent immigrants from the rest of the EEA. Recent non-EEA immigrants, in contrast, are 1.7 percentage points more likely than natives to live in social housing.

\section{[Table 2 here]}

These figures make it clear that European immigrants to the UK are less likely than natives and non-European immigrants to rely on social assistance. Yet, to evaluate the overall fiscal stance of the newly arrived cohorts of immigrants, we need to assess the difference between the amount they paid in taxes and the amount of transfers they received. Table 2 (based on Dustmann and Frattini 2014) does just that and shows that between 2001 and 2011, both EEA and non-EEA immigrants who came to the UK since 2000 paid more in taxes than they received in public spending. Column (1) of the table reports the cumulated net fiscal contributions made by each immigrant group over those 11 years. The positive contribution is particularly evident for UK immigrants from the EEA over the period 2001-2011, EEA immigrants paid (through taxes) over $£ 20$ billion (in 2011 terms) more into the fiscal system than they took out. Importantly, even immigrants from the ten Central and Eastern European countries that joined the EU since 2004 (A10) made positive contribution to the British public finances a $£ 5$ billion, with the remaining $£ 15$ billion being contributed by western European immigrants (i.e. other EEA). At the same time, non-European immigrants who entered the UK since 2000, and who constituted the vast majority of new arrivals (as shown in Figure 4), made a positive fiscal contribution of about $£ 5$ billion. Column (2) displays the revenues/expenditures ratio (i.e. the ratio between the amount paid in and the amount taken out in transfers and public services) for each immigrant group. The figures show that overall, recent EEA immigrants overall paid in $31 \%$ more than they took out. The figure stands at $12 \%$ for A10 
immigrants, and for other European immigrants was even higher at 64\%. Remarkably, the revenues/expenditures ratio of all immigrant groups was higher than that of UK natives, as indicated in column (3). All immigrant groups contributed (in relative terms) more than natives. In fact, the revenues/expenditures ratio of natives was below one - suggested by all values in column (3) being higher than in column (2) - indicating that the net fiscal contribution of natives over the period was negative. ${ }^{11}$

These estimates show that recent immigration to the UK had a positive effect on public finances, yet they are likely to underestimate the total fiscal benefits from immigration. In fact, they do not account for at least two such additional benefits. First, immigration helps in sharing the cost of fixed public expenditures (which account for over $20 \%$ of total public expenditure) among a larger pool of people, thus reducing the per capita financial burden for UK natives. Second, immigrants arrive educated, with their education having been paid by someone else.

Dustmann and Frattini (2014) show that accounting for the first type of implicit savings increases the overall positive fiscal contribution of recent immigrants by almost $£ 24$ billion over the period between 2001 and 2011 ( $£ 2.2$ billion per year, on average). To assess the implicit savings from immigrants arriving in the UK after completing their education abroad (and thus at a point in their lifetime when the discounted net value of their future net fiscal payments is likely to be positive), Dustmann and Frattini (2014) compute the annuity of each worker's education cost per year, and sum this cost up over the period between 2001 and 2011. As the reported level of education would be misleading due to downgrading (discussed above), they assign to each immigrant worker the average years of education of natives working in the same occupation. They then compute how much it would have cost to provide that level of education domestically, rather than importing it from abroad. Based on these numbers, they can compute the total annual cost that an equivalently educated number of UK-born workers would have cost the UK taxpayer. The results of these calculations, reported in column (4) of Table 2, are the implicit savings to the UK taxpayer of immigrants obtaining their education abroad. Over the period 2001 to 2011, the sum of the annuities of the cost of education would have been about $£ 4.3$ billion for recent A10 immigrants, $£ 2.6$ billion for immigrants from other EEA countries, and £11.4 billion for immigrants from outside the EEA.

\footnotetext{
${ }^{11}$ This in turn sums up to the overall deficit the UK was running over the period (see Dustmann and Frattini 2014 for more detail. In that paper, we also provide many different robustness checks.
} 


\section{Discussion and conclusions}

Immigration was a core issue in the run-up to the recent referendum on EU membership in the UK, and it will likely be as important in the upcoming exit negotiations with the EU. In this chapter, we review the issue of immigration by describing not only the particular features of UK immigration, but by also putting immigration to the UK into a wider international context.

The share of foreign-born individuals over the past two decades has increased not just in the UK, but in most industrialised countries, and this trend is likely to continue in the future. Migration of workers across national boundaries is driven by both demand and supply factors - in an increasingly globalised world economy, the competitiveness of national industries depends importantly on their ability to draw on skill pools from around the world. At the same time, the cost of migration has substantially decreased due to huge advances in information and communication technologies and means of travel.

In the international context, the UK has been very fortunate in terms of the type of immigrants it has received, with immigrants to the UK far better educated (on average) in comparison to those to other countries and to natives, and exhibiting high employment and participation rates. Moreover, little evidence exists that the inflows of immigrants over the past two decades has severely harmed native workers' wages and employment possibilities. On the other hand, it is true that many of the newly arrived immigrants do not work in occupations that correspond to their qualifications - a process known as 'downgrading'. However, not only do immigrants - when acquiring complementary skills - rapidly move into occupations that correspond to their skills, they are also likely to be far more productive in jobs for which they are overqualified, which in turn may impact on firms' productivity.

We illustrate that immigrants who arrived in the UK, and particularly those who come from EU countries, made a substantial net contribution to the fiscal coffers, not only by paying more in taxes than they receive in benefits, but also by bringing skills with them that have been financed by their home countries and by contributing to the costs of fixed public goods such as defence and foreign services.

It seems unclear that the ability to control immigration from the EU will lead to a dramatic reduction in immigration. One piece of evidence that points in this direction is that net immigration from non-EU countries (i.e. immigration that is 'controllable' by the government) has been above 100,000 for the entire period of the last government. Economic requirements are likely to be the 
primary reason for these figures being consistently high, and these may not be affected by Brexit. The same needs may well lead to continued immigration from Europe, with many core workers in industry, the NHS, and the education sector being EU nationals. Reductions may be achieved at the lower end of the labour market, though. However, these may be accompanied by economic costs, for instance, by making it harder for the agricultural or retail industries to hire workers. The abolishment of free movement for European workers to the UK will naturally introduce red tape by depriving industry of free access to a potential pool of workers from across the EU, and by regulations and quotas that regulate hiring. Any such restrictions will clearly lead to economic inefficiencies.

What, then, will be the benefits of restricting free movement? To the extent that it will reduce the number of EU workers who arrive in the UK, it will naturally reduce demand for public services such as schools and NHS services, as well as transfers and benefit payments. But, of course, it will also reduce tax receipts. Whether this leads to an economic gain or an economic loss depends on the net fiscal contribution of those who will be restricted from coming to the UK. The work we review in this chapter very clearly shows that, on average, EU workers' fiscal contributions are far higher than the costs they induce by demanding public services and by receiving benefits. But not all EU workers contribute equally, and cutting out the least productive may create some overall fiscal gain. However, any such gain has to be weighed against the cost induced by depriving the public and private sector of access to such workers. Also, the careers of immigrants are dynamic, and many who arrive and start off at very low wages have impressive career paths over their migration histories. In some cases, small family businesses started by immigrants have grown over time to become established high-street names. For instance, Marks \& Spencer developed out of a market stall opened in Leeds in 1884 by the Polish refugee Michael Marks, who successively expanded his business by teaming up with Thomas Spencer in 1894 .

Will it benefit native workers if they compete with fewer immigrants for the same jobs? There has been little evidence that immigration has held back native wage growth except for those at the bottom of the wage distribution, and the effects here are very small. Furthermore, many immigrants - in particular those at the bottom of the wage distribution - work in jobs that produce goods that are tradable. One example is the agricultural industry, which is very labour intensive and where the cost of labour is an essential part of the final output price. Consider the case of asparagus, which is picked by hand, and where the wages of workers will be importantly reflected in the final output price. At present this type of work is done almost exclusively by immigrants, ${ }^{12}$ as natives are not

\footnotetext{
${ }^{12}$ https://www.theguardian.com/business/2013/may/25/migrant-jobs-fruit-farms-kent.
} 
willing to work for the wages on offer. Reducing immigration may lead to higher wages, and to more natives being willing to work in the sector, but also to an increase in the price of asparagus. This new price may be too high for the UK retail sector in comparison to asparagus that can be sourced from other countries where labour is cheaper. This may in turn lead to a reduction in demand in the British asparagus sector, which, rather than employing British workers at higher wages, may be forced to reduce production or to stop production altogether, hurting British workers that have jobs further up the production chain, such as truck drivers, machine operators, or office workers in the asparagus industry. This simple example carries over to many sectors of the economy.

To conclude, it is altogether unclear whether the possibility for the UK government to control immigration from the EU after Brexit will indeed lead to a substantial reduction of overall immigration. Severe restrictions, if imposed, are unlikely to lead to overall economic gains. They may benefit the wages of some particular groups of natives, but these effects are small and likely to be far outweighed by the economic costs discussed above. 


\section{References}

Dustmann, C., F. Fabbri and I. Preston (2005), 'The Impact of Immigration on the UK Labour Market', Economic Journal, 115: F324-41.

Dustmann, C., T. Frattini and C. Halls, C. (2010). "Assessing the fiscal costs and benefits of A8 migration to the UK", Fiscal Studies 31(1): 1-41.

Dustmann, C. and T. Frattini (2014), "The Fiscal Effects of Immigration to the UK", Economic Journal 124: F593-643.

Dustmann, C., T. Frattini and I. Preston (2013), "The Effect of Immigration along the Distribution of Wages", Review of Economic Studies 80(1): 145-173.

Dustmann, C., A. Glitz and T. Frattini (2008), “The Labour Market Impact of Immigration”, Oxford Review of Economic Policy 24(3).

Dustmann, C., U. Schönberg and J. Stuhler (2016), The Impact of Immigration: Reconciling Theory and Evidence, mimeo, University College London.

Lemos, S. and J. Portes (2008), "New Labour? The Impact of Migration from Central and Eastern European Countries on the UK Labour Market”, IZA Discussion Paper No. 3756.

Lucchino, P., C. Rosazza-Bondibene and J. Portes (2012), "Examining the Relationship between Immigration and Unemployment using National Insurance Number Registration Data", NIESR Discussion Paper No. 386.

Manacorda, M., A. Manning and J. Wadsworth (2012), 'The Impact of Immigration on the Structure of Male Wages: Theory and Evidence from Britain', Journal of the European Economic Association 10: 120-51.

Migration Advisory Committee (2012), “Analysis of the Impacts of Migration”, London.

Preston, I. (2014), "The effect of immigration on public finances", Economic Journal, vol. 124(580), pp. F569-92.

United Nations (2011), Population Distribution, Urbanization, Internal Migration and Development, An international Perspective, New York: United Nations Department of Economic and Social Affairs.

United Nations (2015), Trends in International Migrant Stock: The 2015 revision, POP/DB/MIG/Stock/Rev.2015, New York: United Nations Department of Economic and Social Affairs.

Wadsworth, J., S. Dhingra, G. Ottaviano and J. Van Reenen (2016), "Brexit and the Impact of Immigration on the UK", CEP Brexit Analysis No. 5. 
Figures and Tables

Figure 1 - Share of foreign born population in selected countries, 2000 and 2015

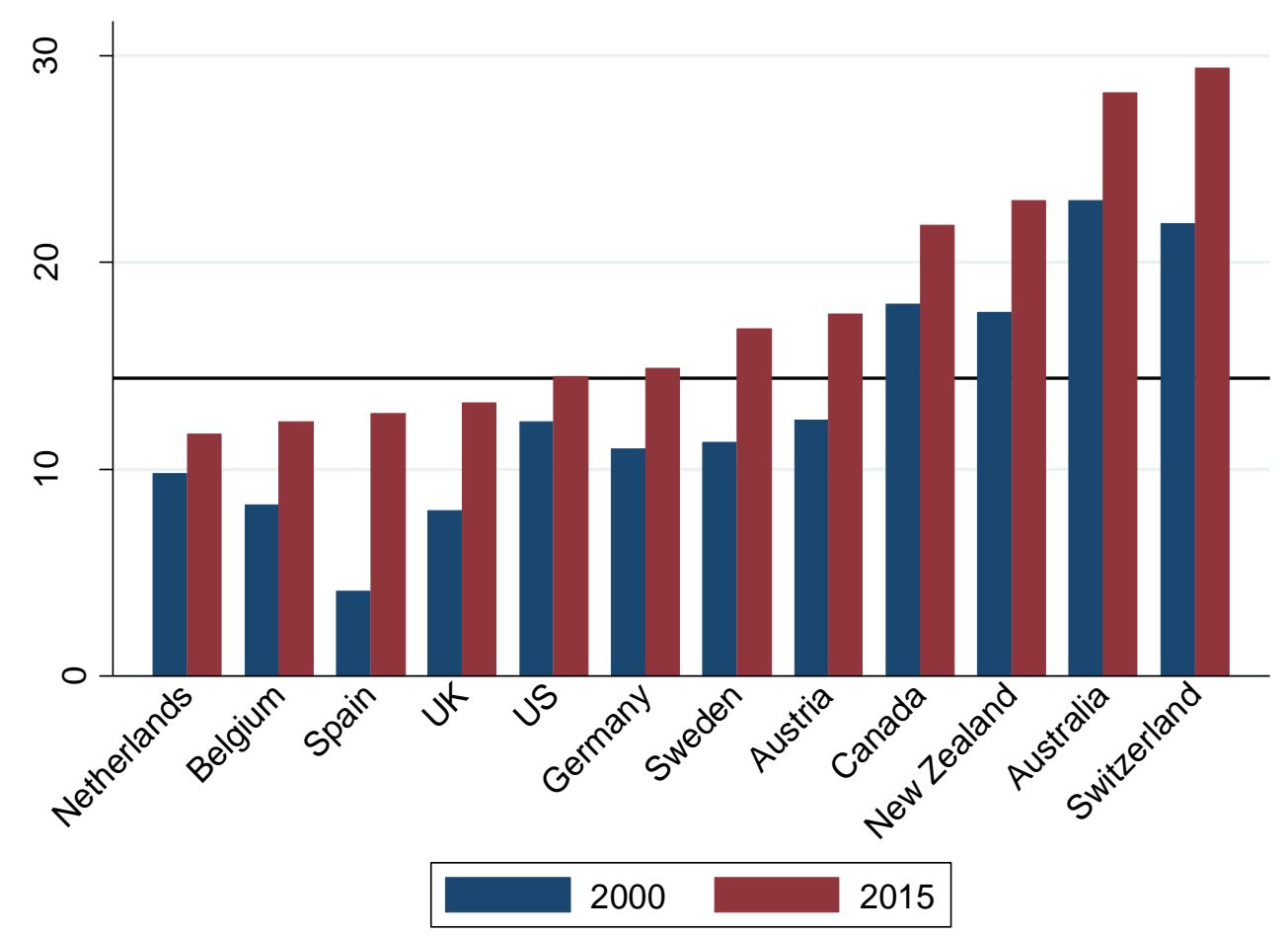

The horizontal line is the 2015 average for the countries shown on the figure weighted by their total population

Source: Our elaboration on United Nations, Trends in International Migrant Stock 


\section{Figure 2 - Most important issues facing the country}
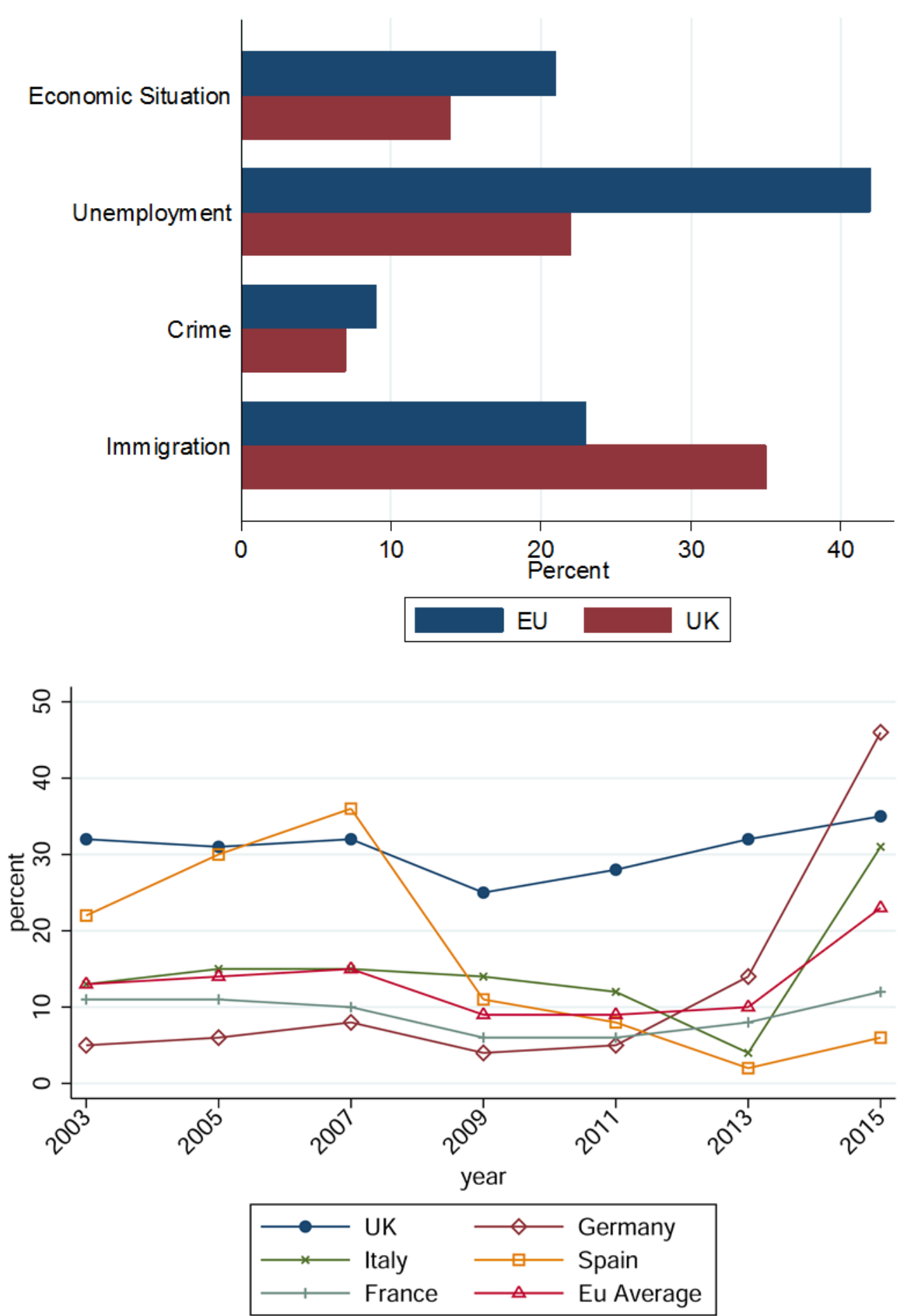

The top graph shows the share of respondents who believe that one of the two most important issues facing their country is the economic situation, unemployment, crime, or immigration, respectively, on average across the EU (blue bars) and in the UK (red bars) in 2015. The bottom graph displays the evolution of the share of respondents claiming that one of the two most important issues facing their country is immigration between 2003 and 2015, in the UK, Germany, Italy, Spain, France, and the average across the EU.

Source: Authors' elaboration on data from Eurobarometer. 
Figure 3 - Share of immigrants with tertiary education in selected EU countries, 2015

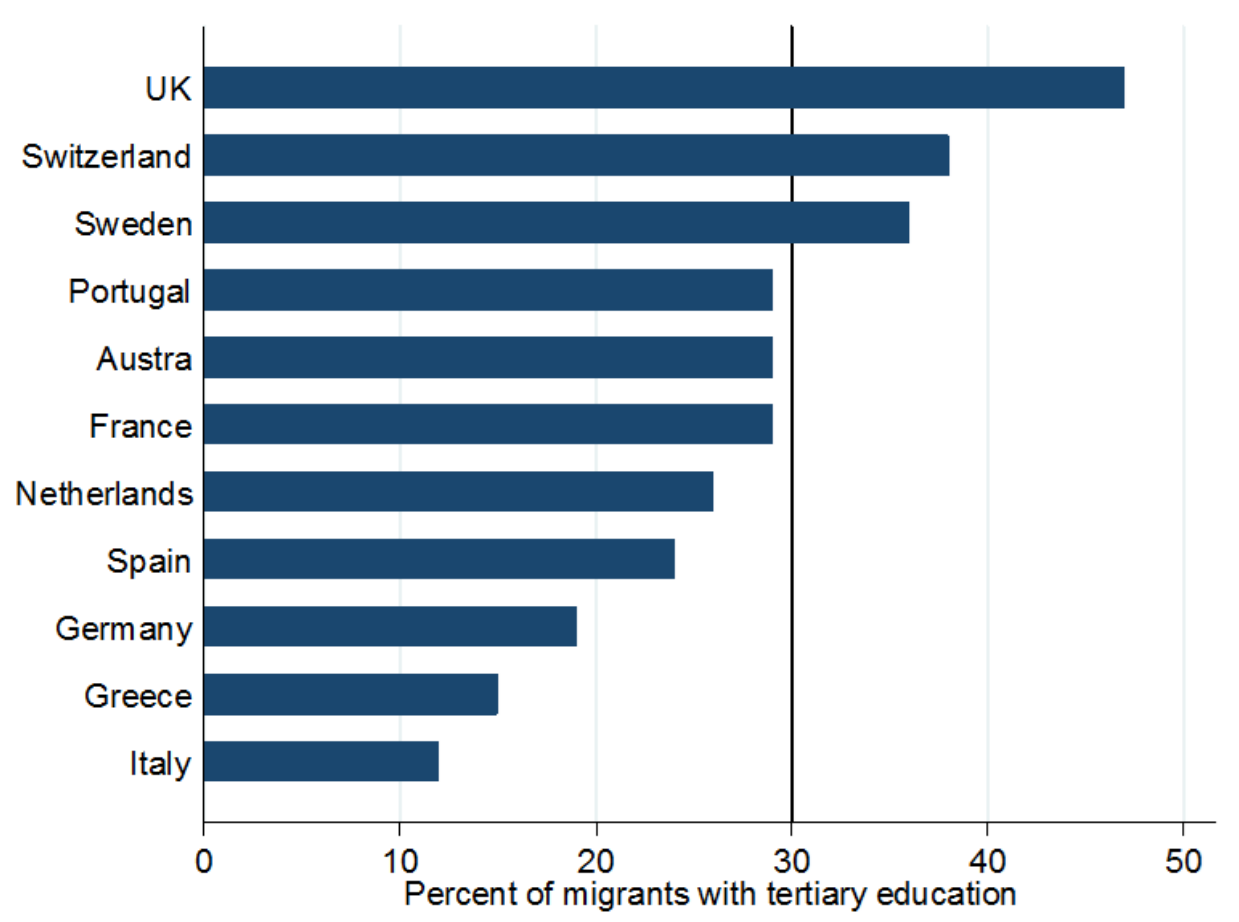

The figure shows the share of immigrants with tertiary education (ISCED levels 5-8) out of total immigrants in each country, and on average across the EU 28 (vertical line), in 2015. Immigrants are defined as foreign born, except for Germany where they are defined as foreign nationals. Source: EUROSTAT

Figure 4 -Net annual immigrant inflows, 2002-2015

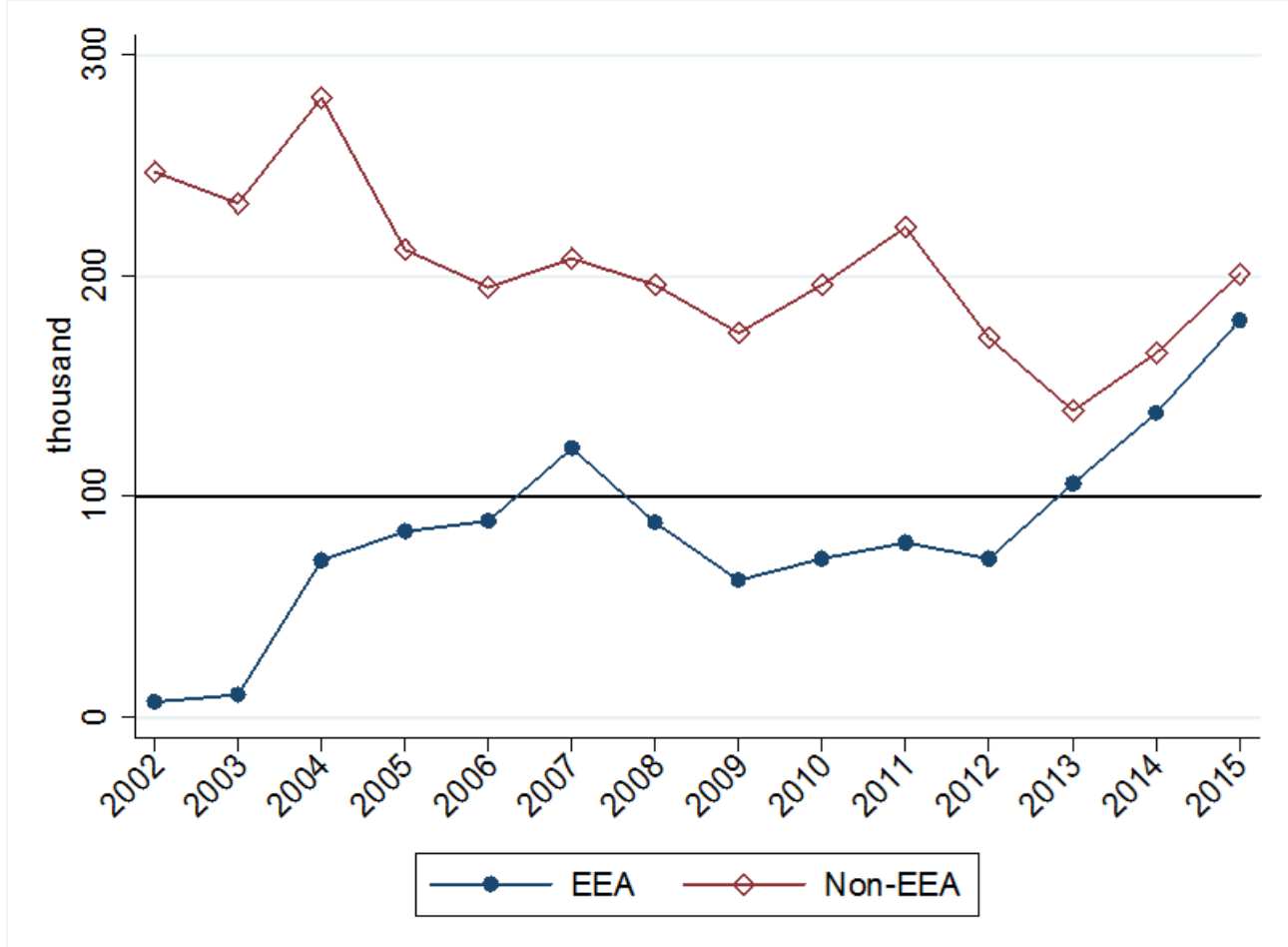

The figure reports the net annual inflow of EEA (full dots) and non-EEA (empty diamonds), for each year 2002-2015.

Source: LTIM 
Table 1 Natives' and immigrants' selected characteristics, 2015

\begin{tabular}{lcccc} 
& Natives & \multicolumn{3}{c}{ Migrants } \\
& & All & EEA & non EEA \\
\hline \multicolumn{1}{c}{ Age } & & & & \\
Mean & 39.6 & 39.8 & 37.3 & 41.1 \\
\% age 23-65 & 53.3 & 72.0 & 71.4 & 72.3 \\
\% above 65 & 18.5 & 11.8 & 10.7 & 12.3 \\
$\quad$ Education & & & & \\
Low (16 or under) & 44.5 & 17.5 & 12.5 & 20.0 \\
$\begin{array}{l}\text { Medium (17- 20) } \\
\text { High (21 or older) }\end{array} \quad 29.6$ & 32.9 & 39.4 & 29.7 \\
$\quad$ Labour market & 23.9 & 41.7 & 42.6 & 41.2 \\
$\begin{array}{l}\text { Employment rate 23-65 } \\
\text { Mean weekly wages }\end{array}$ & 77.5 & 74.1 & 82.8 & 69.8 \\
\hline The table reports selected sum & 478 & 490 & 452 & 514 \\
\hline
\end{tabular}

The table reports selected summary characteristics of natives and immigrants living in the UK in 2015. Columns 3 and 4 break down the immigrant population in immigrants from the European Economic Area (EEA) and from outside the European Economic Area (non EEA). Low education: left full time education aged 16 or younger; medium education: left full time education between 17 and 20; high education: left full time education at age 21 or above. Employment rate 23-65 is defined as the ratio of employed individuals in the age range 23-65 to total population in the same age range. Source: Authors' elaboration on UK LFS.

Figure 5 - Native unemployment and working age immigration

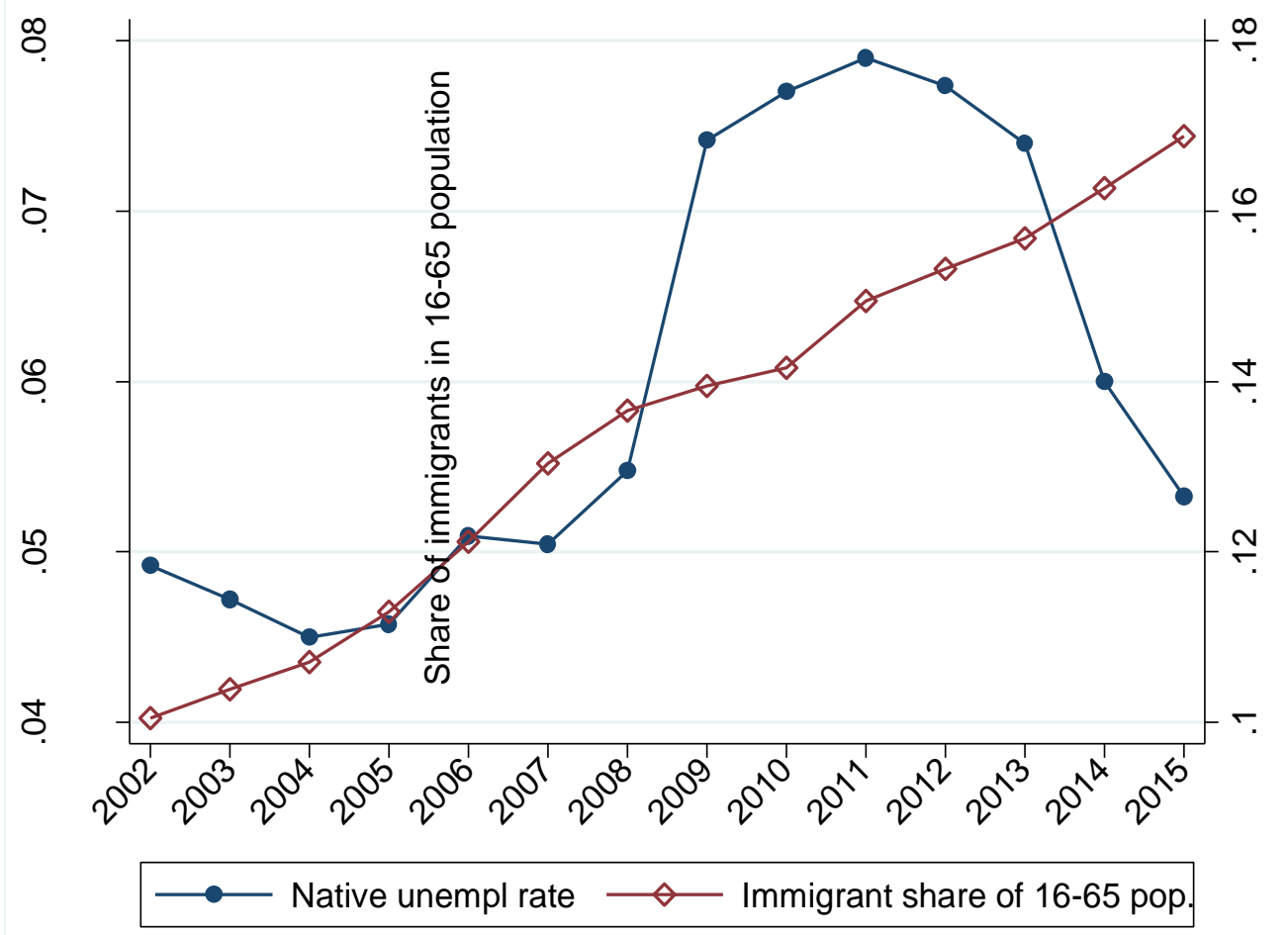

The figure reports the native unemployment rate and the share of immigrants in working age population. The native unemployment rate (full dots) is reported on the left hand axis and the proportion of 16 to 65 year olds that are foreign born (empty diamonds) is reported on the right hand axis. Source: our elaboration on the UK Labour Force Survey 
Figure 6 - Position of EEA and non-EEA immigrants in wage distribution, by years since migration

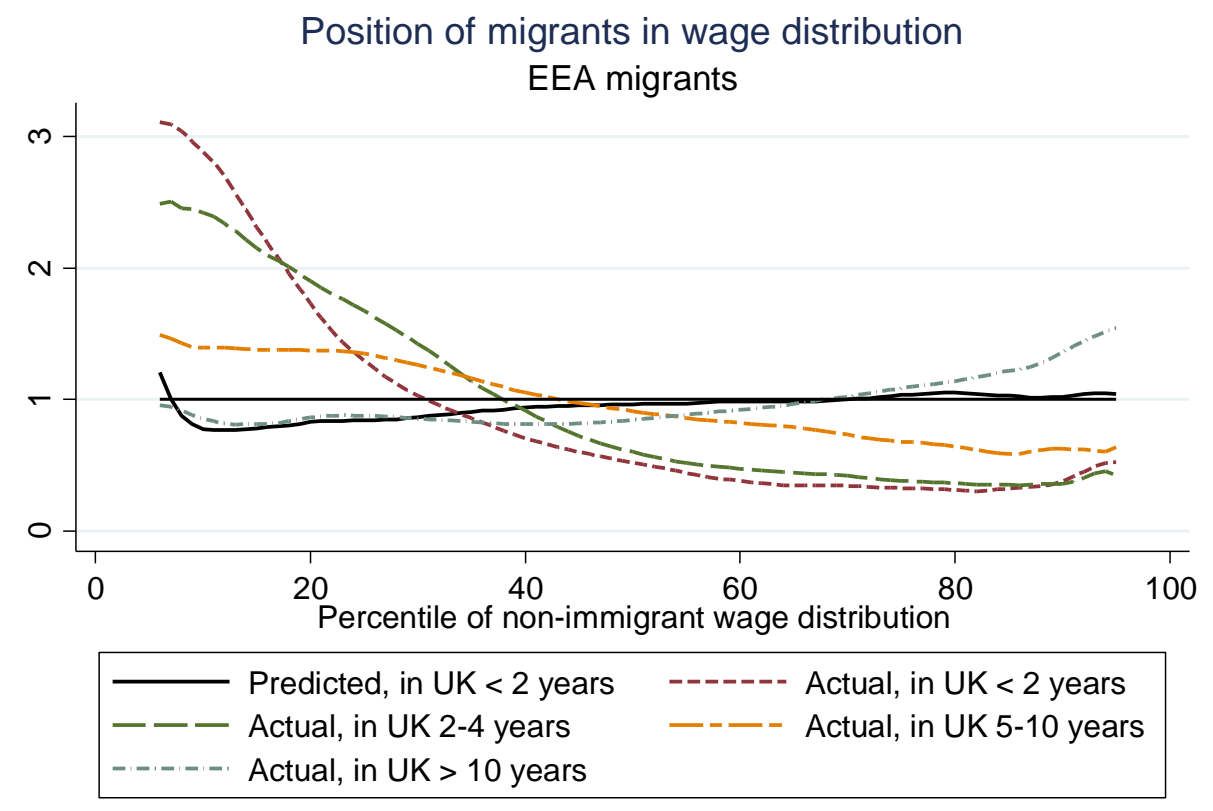

Source: LFS, various years

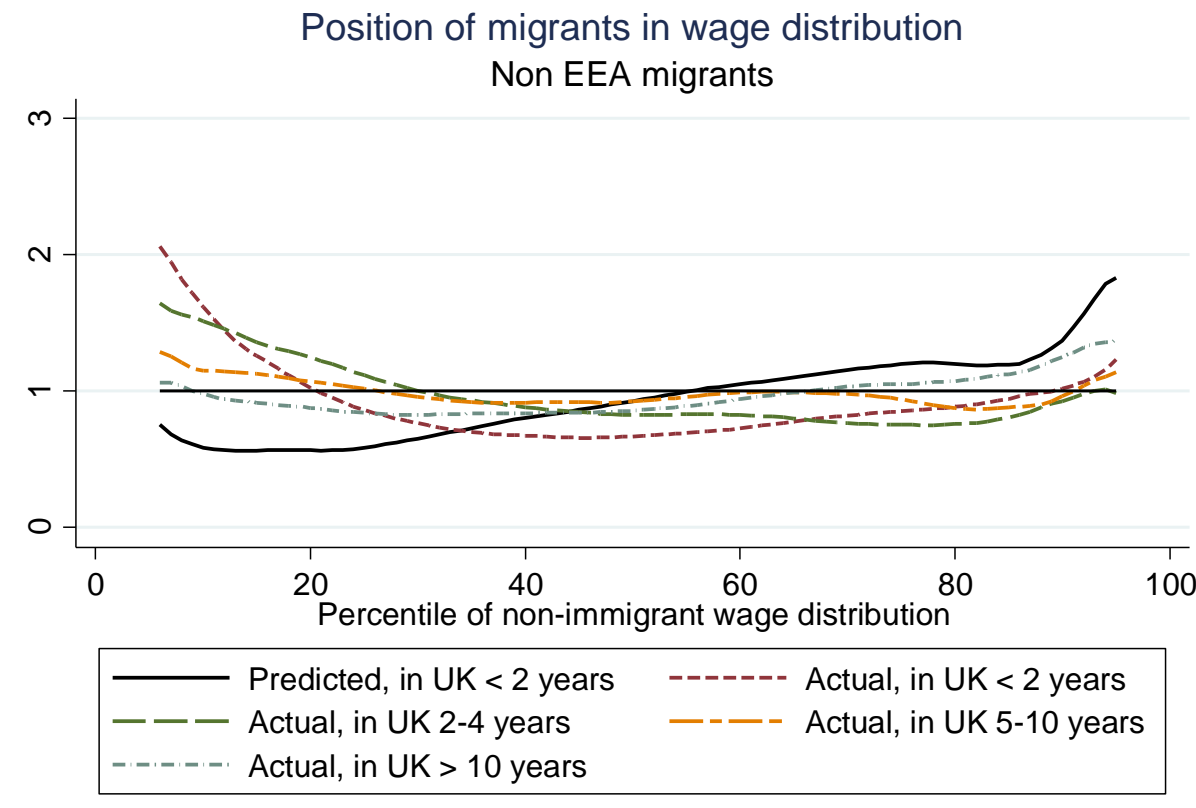

Source: LFS, various years

The figures show kernel estimates of the predicted (solid line) and actual (dashed lines) density of EEA (top figure) and non-EEA (bottom figure) immigrants in the non-immigrant wage distribution, distinguishing by years since migration. The horizontal line shows as a reference the nonimmigrant wage distribution. The kernel estimates are above the horizontal line at wages where immigrants are more concentrated than natives, and below the horizontal line at wages where immigrants are less concentrated than natives. The estimates for the actual distribution distinguish between migrants who have been in the country for less than 2, between 2 and 4 years, between 5 and 10 years and more than 10 years.

Source: Authors' elaboration on LFS data, years 2002 to 2015. 
Table 2 - Fiscal contributions of immigrants, 2001-2011

(1)

Net fiscal
contributions
(million GBP)

(2)

Revenues/
expenditures
ratio

(3)

Revenues/ expenditures ratio, relative to natives
(4)

Cost of homecountry education

\begin{tabular}{ccccc} 
Recent EEA & 20,215 & 1.311 & 1.464 & 6,902 \\
$\quad$ of which & & & & \\
$\quad$ Recent A10 & 4,961 & 1.120 & 1.252 & 4,338 \\
Recent Other EEA & 15,255 & 1.640 & 1.833 & 2,564 \\
Recent Non EEA & 5,207 & 1.033 & 1.154 & 11,412 \\
\hline
\end{tabular}

The table reports, for EEA immigrants arrived since 2000, and broken down into immigrants from the ten Central and Eastern European countries that joined the EU since 2004 (A10) and from Western Europe (other EEA), and for non-EEA immigrants arrived since 2000, and cumulated over fiscal years 2001-2011: column (1) the overall net fiscal contribution, expressed in 2011 equivalent GBP; column (2) the ratio of revenues contributed to expenditures received; column (3) the revenues/expenditures ratio for the respective immigrant group relative to natives; column (4) reports the cumulated annual cost that the UK should have borne if employed immigrants had been educated domestically.

Source: data from Dustmann and Frattini (2014) 